\title{
GAMBARAN PARTISIPASI IBU BALITA DAN PENGETAHUAN IBU BALITA DI POSYANDU WILAYAH KERJA PUSKESMAS TELUK DALAM
}

\author{
Description of Participation and Knowledge of Children Mother in Posyandu \\ Teluk Dalam Public Health Center \\ Yasir Farhat \\ Poltekkes Kemenkes Banjarmasin \\ Email : yasirfarhat@yahoo.co.id
}

\begin{abstract}
Mother's activity in every posyandu activity will certainly affect the state of the nutritional status of her toddler. Because one of the objectives of the posyandu is to monitor the improvement of the nutritional status of the community, especially children under five and pregnant women. In order to achieve this, mothers with children under five should be active in posyandu activities so that their toddler's nutritional status is monitored. In accordance with the results of the monthly report in the Teluk Dalam Puskesmas in 2016 the coverage of community participation (D / S) for infants was $76.72 \%$ while in infants was $72.00 \%$, while the target to be achieved was $85 \%$. To know the description of the participation of mothers of children under five and the knowledge of mothers of children under five in the Posyandu working area of the Teluk Dalam Public Health Center in Central Banjarmasin District 2017. Types of descriptive observational research with a case study approach research design. The population is mothers who have toddlers with low participation and the sample is a total population of 20 people. Data processing using computer programs, namely SPSS 17 software for windows and fund analysis using univariate analysis. The participation of active under-fives (45\%) and inactive (55\%) while the level of knowledge of good mothers (20\%), is sufficient (45\%) and less (35\%). The level of knowledge of mothers is still lacking and there is still much participation in weighing.
\end{abstract}

Keywords: Knowledge, participation of toddler mothers

\begin{abstract}
Abstrak
Keaktifan ibu pada setiap kegiatan posyandu tentu akan berpengaruh pada keaadaan status gizi anak balitanya. Karena salah satu tujuan posyandu adalah memantau peningkatan status gizi masyarakat terutama anak balita dan ibu hamil. Agar tercapai itu semua maka ibu yang memiliki anak balita hendaknya aktif dalam kegiatan posyandu agar status gizi balitanya terpantau. Sesuai dari hasil laporan bulanan Puskesmas Teluk Dalam pada tahun 2016 cakupan partisipasi masyarakat (D/S) bayi adalah $76,72 \%$ sedangkan pada balita sebesar $72,00 \%$, sedangkan target yang harus dicapai adalah $85 \%$. Untuk mengetahui gambaran partisipasi ibu balita dan pengetahuan ibu balita di posyandu wilayah kerja Puskesmas Teluk Dalam Kecamatan Banjarmasin Tengah Tahun 2017. Jenis penelitian observasional Deskriptif dengan rancangan penelitian pendekatan studi kasus. Populasi adalah ibu yang mempunyai balita dengan partisipasi rendah dan sampelnya yaitu total populasi sebanyak 20 orang Pengolahan data menggunakan program komputer yaitu software SPSS 17 for windows dan analisis dana menggunakan analisis univariat. Partisipasi ibu balita yang aktif $(45 \%)$ dan yang tidak aktif (55\%) sedangkan tingkat pengetahuan ibu yang baik (20\%), cukup (45\%) dan kurang (35\%). Tingkat pengetahuan ibu masih banyak yang kurang dan partisipasi penimbangan masih banyak yang tidak aktif.
\end{abstract}

Kata kunci : Pengetahuan, partisipasi ibu balita 


\section{PENDAHULUAN}

Posyandu (Pos Pelayanan Terpadu) adalah salah satu bentuk upaya kesehatan bersumber daya masyarakat yang dikelola dan diselenggarakan oleh bersama masyarakat dalam penyelenggaraan pembangunan kesehatan. Posyandu memberdayakan masyarakat dan memberikan kemudahan kepada masyarakat dalam memperoleh pelayanan kesehatan dasar untuk mempercepat penurunan angka kematian ibu dan bayi. Dengan posyandu dapat memantau pertumbuhan balita sehingga dapat terdeteksi apabila ada penyimpangan pertumbuhan dan dapat dilakukan penanggulangan sedini mungkin sehingga tidak terjadi gangguan pada proses tumbuh kembang balita. Peran posyandu sangat penting karena posyandu sebagai wahana pelayanan berbagai program yaitu KIA, KB, Imunisasi, Gizi dan penanggulangan diare (Notoatmodjo, 2007).

Menurut penelitian Farida tahun 2012 kunjungan balita diposyandu berkaitan dengan peran ibu sebagai yang paling bertanggung jawab terhadap kesehatan balitanya, karena balita sangat bergantung pada ibunya.

Menurut Mikklesen (2003), pertisipasi adalah keterlibatan masyarakat secara sukarela atas diri mereka sendiri dalam membentuk perubahan yang diinginkan. Partisipasi juga dapat diartikan Mikkelsen sebagai keterlibatan masyarakat dalam upaya pembangunan lingkungan, kehidupan dan diri mereka sendiri. Menurut Madanijah \& Triana (2007) bahwa tingkat kehadiran ibu dikategorikan baik apabila garis grafik berat badan pada KMS tidak pernah putus (hadir dan ditimbang setiap bulan di posyandu), sedangkan apabila grafik tersambung dua bulan berturut-turut dan kurang apabila garis grafik pada KMS tidak terbentuk atau tidak hadir dan tidak ditimbang setiap bulan di posyandu.

Pengetahuan merupakan tahap awal untuk seseorang berbuat sesuatu dan pengetahuan tentang apa yang dilakukan untuk membuat seseorang mengetahui langkah selanjutnya yang harus diperbuat, seperti halnya seorang kader posyandu yang harus mengetahui tugas yang diembannya sehingga dapat memberikan pelayanan maksimal kepada masyarakat dalam mengelola posyandu.

\section{BAHAN DAN METODE}

Jenis penelitian ini adalah observasional deskriptif dengan rancangan penelitian studi kasus, dilakukan di Wilayah Kerja Puskesmas Teluk Dalam dan dimulai sejak bulan maret 2017. Populasi penelitian adalah ibu yang mempunyai balita. Sampel penelitian adalah ibu di posyandu yang kunjungan balitanya rendah. Data dalam penelitian ini data primer yaitu tingkat pengetahuan ibu balita dan kunjungan ibu balita ke posyandu, sedangkan data sekunder meliputi gambaran umum Wilayah Kerja Puskesmas Teluk Dalam. Data pengetahuan dikumpulkan dengan wawancara menggunakan kuesioner dan Data kunjungan ibu balita keposyandu diperoleh dari laporan tahunan Puskesmas. Pengolahan dan analisis data menggunakan program komputer yaitu software SPSS 17 for windows.

\section{HASIL DAN PEMBAHASAN}

Tabel 1. Distribusi Frekuensi Keaktifan Ibu Balita datang keposyandu dan Pengetahuan Ibu Balita di Wilayah Kerja Puskesmas Teluk Dalam

\begin{tabular}{lcc}
\hline Variabel & $\mathrm{n}$ & $\%$ \\
\hline Keaktifan Ibu Balita & & \\
$\quad$ Aktif $(\geq 4$ kali) & 9 & 45 \\
Tidak Aktif $(<4$ kali) & 11 & 55 \\
Pengetahuan & & \\
$\quad$ Baik & 4 & 20 \\
Cukup & 9 & 45 \\
$\quad$ Kurang & 7 & 35 \\
\hline Jumlah & $\mathbf{2 0}$ & $\mathbf{1 0 0}$ \\
\hline
\end{tabular}

\section{Partisipasi Ibu Balita}

Pada tabel 1 bahwa sebagian besar ibu balita yang berkunjung ke posyandu aktif (55\%) dan ibu balita yang tidak aktif berkunjung ke posyandu (45\%). Hal ini menunjukkan bahwa sebagian besar ibu-ibu di wilayah kerja Puskesmas Teluk Dalam tidak berperan aktif dalam memantau perkembangan anak dan berkunjung keposyandu. Ketidakaktifan ibu terlihat dari buku KMS yang dimiliki ibu yang berkunjung < 4 kali dalam 6 bulan terakhir dimana tingkat kehadiran ibu dikategorikan tidak aktif apabila garis 
grafik berat badan pada KMS pernah putus dan tidak terbentuk atau tidak hadir atau tidak di timbang setiap bulan di posyandu (Madanijah \& Triana, 2007).

Menurut Depkes RI (2009) secara khusus keaktifan ibu balita ke posyandu dapat diartikan sebagai tingkat kehadiran dalam kegiatan penimbangan. Kehadiran itu dapat pula diartikan dengan partisipasi masyarakat (D/S). Adapun faktor yang dapat mempengaruhi keaktifan ibu balita ke posyandu dapat dikarenakan tingkat pengetahuan yang rendah, sikap dan pekerjaan.

\section{Tingkat Pengetahuan}

Pada tabel 1 bahwa tingkat pengetahuan ibu sebagian besar cukup (45\%) namun masih banyak juga ibu yang berpengetahuan kurang (35\%) sedangkan tingkat pengetahuan ibu yang masih baik hanya (20\%). Hal ini menunjukkan banyaknya responden yang mempunyai pengetahuan yang cukup dikarenakan bahwa ibu-ibu balita sudah sebagian mengetahui tentang manfaat dan guna posyandu karena sering mndengarkan informasi tentang penimbangan di posyandu. Faktor pengetahuan ibu balita dipengaruhi oleh kebiasaan mendengarkan informasi-informasi dari petugas kesehatan.

Kurangnya pengetahuan menjadi salah satu penyebab munculnya kurang aktifnya partisipasi ibu membawa balita ke posyandu, sehingga kurangnya kemampuan untuk menerapkan informasi tentang gizi dalam kehidupan sehari-hari. Ibu yang tidak memiliki cukup pengetahuan tentang posyandu akan memilih untuk tidak membawa anaknya ke posyandu. Hal ini disebabkan pada anak usia 1 tahun keatas dianggap oleh ibunya telah lengkap imunisasinya sehingga tidak perlu lagi dibawa ke posyandu. Disamping ini anak sudah ada rasa takut dan rewel dan tidak mau ditimbang (Suhardjo, 2003).

Berdasarkan pertanyaan-pertanyaan tentang tingkat pengetahuan responden masih kurang memahami, diantaranya mengenai grafik garis pertumbuhan balita sehat pada KMS (75\%), mengapa anak perlu di imunisasi $(70 \%)$, apa arti jika berat badan anak berada di atas garis hijau 3 kali berturutturut $(55 \%)$, mengenai keadaan anak apabila umur balita bertambah tetapi berat badan tidak naik 3 kali berturut-turut bahkan mengalami penurunan berat badan (50\%), kegunaan KMS (50\%), manfaat menimbang balita ke posyandu (45\%). Berdasarkan data diatas dapat diketahui bahwa tingkat pengetahuan responden masih banyak kurang.

\section{KESIMPULAN}

Ibu balita di wilayah kerja Puskesmas Teluk Dalam yang memiliki tingkat pengetahuan cukup sebesar $45 \%$, baik $20 \%$ dan kurang $35 \%$. Ibu balita yang aktif ke Posyandu di wilayah kerja Puskesmas Teluk Dalam yaitu sebesar $45 \%$ dan yang tidak aktif datang ke posyandu sebesar 55\%. Bagi petugas Posyandu diharapkan memberikan motivasi pada ibu untuk membawa anaknya ke posyandu. Bagi Puskesmas Teluk Dalam diharapkan memberikan informasi dan penyuluhan tentang pentingnya membawa anak ke Posyandu. Bagi peneliti selanjutnya diharapkan melanjutkan penelitian dengan faktor-faktor lain yang mempengaruhi keaktifan ibu balita ke Posyandu.

\section{DAFTAR PUSTAKA}

Depkes RI, 2009. Sitem Kesehatan Nasional. Jakarta.

Farida, H. (2012). Hubungan Pendidikan, Pekerjaan, Pengetahuan Dan Kepuasan Ibu Terhadap Posyandu Dengan Frekuensi Kunjungan Balita Ke Posyandu Di Puskesmas. Jurnal Kedokteran Lampung Mangkurat, 1 (4)

Kristiani, 2007. Hubungan Pengetahuan Ibu Balita Dengan Kepatuhan Kunjungan Balita Ke Posyandu Di Desa Sumberejo Kecamatan Mranggen Kabupaten Demak

Madanijah, S. dan Triana, N., 2007. Hubungan antara Status Gizi Masa Lalu Anak dan Partisipasi Ibu di Posyandu dengan Kejadian Tuberkolosis Pada Murid Taman Kanak-Kanak. Jurnal Gizi dan Pangan

Mikkelsen, B., 2003. Metode penelitian partisipatorid dan Upaya-upaya Pemberdayaan. Sebuah Buku Pegangan Bagi Para Praktisi Lapangan. Jakarta : Yayasan Obor Indonesia

Notoatmodjo, S., 2007. Ilmu Kesehatan Masyarakat, Ilmu dan Seni. Jakarta : Rineka Cipta.

Suhardjo. 2003. Berbagai Cara Pendidikan Gizi. Jakarta. Bumi Aksara 